\title{
MERKWAARDIGE KOKERVERSIERINGEN UIT DE ZUIDER- EN OOSTERAFDEELING VAN BORNEO.
}

DOOR

J. A. L OEB Ė $\mathrm{J}$ UN.

Het is wel eigenaardig, dat juist uit de Zuider- en Oosterafdeeling van Borneo bamboe-kokers in de mij bekende verzamelingen vrijwel ontbreken. Het bamboe-snijwerk uit Midden-Borneo is prachtig vertegenwoordigd in het Rijks Ethnographisch Museum te Leiden en in het Museum für Völkerkunde te Leipzig, terwijl in de Verzameling der voormalige Indische Instellling te Delft een belangrijk aantal kokers uit de Wester-Afdeeling aanwezig is.

Kokers uit Noord- en Noordoost-Borneo kan men in de Ethnographische Afdeeling van het British Museum antreffen. "Vereinzelt" vindt men exemplaren uit bovengenoemde deelen van Borneo in andere Musea verspreid.

Maar voor de Zuider- en Ooster-Afdeeling moet een uitzondering gemaakt worden. Niet meer dan vijf versierde exemplaren zijn mij bekend. Doch hier maakt de kwaliteit de kwantiteit weder goed! Het zijn zonder uitzondering bizonder verzorgde werkstukken, die bovendien in hun versiering geheel af wijken van de bekende Borneo-ornamenten.

Niet alleen uit een artistiek oogpunt zijn zij belangrijk, ook in wetenschappelijk opzicht! Deze kokers toch kunnen als authentieke illustraties dienen bij fragmenten uit de Dajak'sche mythologie. De versiering der eerste drie blijft zuiver-ornamentaal in uitvoering, terwijl die der twee laatste een uitvoerige, pictographische voorstelling te zien geeft, die onder de Indische bamboekokers als groote zeldzaamheid vermeld mag worden.

De af beeldingen $1-3$ toonen ondanks den verschillenden loop der lijnen groote overeenkomst. Het middenvak $a$ van fig. 3 vertoont naast enkele dierfiguren lange lijnen, die zich in voluten krullend vereenigen. Deze lange lijnen zijn bezet met sterk ingekrulde spiralen 
in enkelvoudigen vorm, dus afwijkend van de bekende, dubbele spiraal, die zooveel in de Borneo-ornamentiek voorkomt en met voorliefde door kunstige détails wordt versierd. Dat is hier niet het geval! De eenvoudige spiraal is uitsluitend gebruikt en door de regelmatige herhaling verkrijgt het geheel een bizonder cachet, een streng aspekt. Fig. 1 en 2 zijn zelfs geheel met deze spiraalmotieven bedekt (met uitzondering der randversiering) en geven bovengenoemde eigenschappen nog sterker te zien.

In ornamenttype herinneren zij eenigszins aan het zoo merkwaardige vlechtwerkje uit de Zuider- en Oosterfdeeling, dat het Rijks Ethnograpisch Museum te Leiden (ser. 122-22) bezit en door mij in het onlangs verscheuen Bamboe-Bulletin (Bulletin $\mathrm{N}^{\circ} 43$ van het Koloniaal Museum te Haarlem) als plaat VI is afgebeeld. Op het derde vak van dit vlechtwerkje is zeer duidelijk een gestileerde boom te herkennen, die op een heuveltje groeit, waaruit twee speren steken. Ook de top van den boom vertoont een groote lanspunt. De takkeu zijn parallel gerangschikt en dragen naast de reeds besproken enkele spiralen der bamboe-kokers ruitvormige aanhangsels.

Met dit vlechtwerkje, dat, kurieus genoeg, ook weer uit hetzelfde deel van Borneo komt, wordt de versiering der kokers duidelijker. Op het drietal kokers ontwaart men den stam als uitgangspunt der lijnen. In fig. 1 ' buigt zich aan weerszijden van den stam een groote voluut uit, waaraan de lange lijnen naar beneden hangen. Deze strenge rangschikking - hier ongeveer diagonaal behandeld, op het vlechtwerkje in schuine richting - gaat op de beide andere kokers verloren. In fig. 2 is zelfs een mooi vlakornament ontstaan, terwijl fig. 3 door onregelmatigheid de aandacht trekt. Hier vindt men aan de beide randen der afbeelding een tweede boomtype, waaruit eveneens de spiraal-lijnen voortkomen.

Het hoofdmotief dezer kokerversieringen dankt naar alle waarschijnlijk zijn ontstaan aan de boomkultuur, overblijfsel der Hindoeperiode op Borneo. Grabowsky ${ }^{2}$ vermeldt blz. 121 verschillende mythische boomen. "Die Sangiang oder Luftgeister, sind gute und hülfreiche Wesen. Sie wohnen in dem lewu Sangiang oder Sangiang-

1 Zie de geheele afbeelding van dezen koker in den "Catalogus van 's Rijks Ethnogr. Museum. I. Borneo. door Dr. H. H. Juynboll." Leiden 1910. Plaat II, fig. 3 .

${ }^{2}$ Die Theogenie der Dajaken auf Borneo. Nach eigenen Aufzeichnungen und der vorh. Litteratur bearbeitet von F. Grabowsky. (Int. Archiv. f. Ethnographie). Band V. 1892. 
lande, das irgendwo im Himmel "über dem Nebelmeere und unter dem Himmel von Mahatara" gelegen und so gross ist, dass es von 160 Flüssen durchströmt wird." blz. 122.... Es wachsen dort z. B. nur Fruchtbäume, deren Früchte "endjong", manontong tahaseng d. h. "den Athem aneinandersetzen, verlängern"; andere Bäume, deren Früchte panarang atäi "das Herz hell, weiss machen". Es wachsen dort die batang garing, Garingbäume, die feines Zeug statt der Blätter haben, deren Blüthen goldene Ringe und deren Früchte schön bearbeitete Achatperlen (lameang) sind. Auch wachsen dort Aerang-Bäume, deren $\mathrm{Holz}$ ein Zaubermittel ist um reich zu werden und Handjunan-Bäume, deren Blätter feines Zeug und deren Früchte Gold sind."

Verscheidenheid is er dus genoeg onder de boomen in het Sangiangland en het zou moeilijk zijn te ontdekken, welke wonderboom hier afgebeeld is, als niet een andere kenner van dit deel van Borneo te hulp kwam.

Den Hamer ${ }^{1}$ nl. beschrijft een tatoeëer-patroon, dat de Biadjoe's op den rug aanbrengen en uit lange, parallel loopende lijnen bestaat, met spiralen bezet. En dit patroon heet batang garing!

De boom dus met fijne stoffen als bladen; met gouden ringen als bloesems en met agaatkralen als vruchten!

Intusschen is hier weinig van die weidsche pracht overgebleven. Alleen de ruitvormige aanhangsels, die naast de spiralen op den boom van het genoemde vlechtwerk voorkomen, zou men als de mooi bewerkte agaatkralen of versieringen van agaat kunnen aanduiden. Doch al mist men de door Grabowsky geciteerde kostbaarheden, is het toch waarschijnlijk, dat hier dezelfde wonderboom is afgebeeld. Van alle boomen is de batang garing toch de kostbaarste, staat door de agaatkralen zelfs boven de handjoenan-boomen. En nu is het de groote vraag, of niet door dien spiralen-tooi de kostbaarheid van den batang garing uitgedrukt moet worden. Bij de meeste primitieve volken toch bestaan de oudste sieraden uit vastgekrulde spiralen, omdat ze het eenvoudigst te vervaardigen waren. Bij de Batak'sche sieraden bijv. overheerscht het aaneengesloten spiraalmotief alle andere bijkomstigheden, komt op armbanden dikwijls als uitsluitende versiering voor. Ook onder het Dajak'sche metalwerk vindt men meermalen dit spiraal-motief als versiering gebruikt. Dus

1 C. den Hamer. Iets over het tatoueeren of toetang bij de Biadjoe-stammen in de Z. O. Afd. van Borneo.

Tijdschrift v. ind. t. l. en v. 1885 XXX blz. 455. 
is het geenszins onwaarschijnlijk, dat de zoo opzettelijk gebruikte spiralen de kostbaarheden aan den batang garing moeten voorstellen.

Ook op den mooien koker van fig. 4 zijn in het bovenvak de verschillende mythische boomen afgebeeld, die ietwat naturalistischer zijn in vorm dan de reeds behandelde, maar toch duidelijk hun van de aardsche boomen afwijkenden vorm te zien geven. De middelste boom herinnert eigenlijk meer aan de batang garing, door Grabowsky beschreven, dan die der andere kokers. De bladen bestaan hier uit driemaal gevouwen stoffen, de bloesems uit zeven ringen in bloemvorm geschikt en in den vorm van vruchten hangen snoeren kralen omlaag.

Echter behoeft de duidelijke af beelding van den batang garing op dezen koker die van de andere niet onzeker te maken. Den Hamer geeft toch als kenmerken van het batang garing-patroon de spiralen en de lange lijnen aan, wat tevens de kenmerkende eigenschappen der genoemde bamboe-kokers ook zijn. Ook is op de bamboe-kokers der afb. $1-3$ het boom-motief meer in het zuiver-ornamentale overgegaan en op dien weg gaat steeds veel verloren, verdwijnt de oorspronkelijke vorm dikwijls geheel.

En bij den koker van fig. 4, dit eenig prachtstuk in het Rijks Ethnographisch Museum te Leiden, in 1893 (ser. 942-32) van den toenmaligen controleur H. F. Hesselaar aangekocht, is niet alleen een kunstig snijder bij uitnemendheid aan het woord, maar tevens een goed kenner van zijn stamgeloof.

Zoo vindt men in den boom ter rechter zijde van vak $d$ van bovengenoemden koker den boom van belofte terug, waarop de mahadoera, de Garoeda zetelt. Hiervan vertelt Grabowsky blz. 130 "Mahadura. Ein grosser fabelhafter Vogel, so gross wie ein Haus. Mitten in der See, auf dem Batang kaju djandi, dem Verheissungsbaume, hat er sein Nest. Selbst die Sangiang fürchten ihn". Ook deze beschrijving komt precies met de afbeelding overeen. In verhouding tot de menschfiguren doet de mahadoera buitengewoon groot, is ook in vorm een fabelachtige verschijning, die eenigszins herinnert aan de garoeda-motieven op Javaansche batik's. De wonderboom is hier als eeu soort palm voorgesteld en als vruchten hangen geheimzinnige pakjes omlaag. Het staan van den boom midden in het meer wordt hier voorgesteld door de plaatsing tusschen twee heuveltjes.

Ook de aapvormige wezens, die in de andere boomen springen en klimmen of verscholen in den grond zitten, worden door Grabowsky beschreven. (blz. 129) 
"Njaring, auch Njaring mambulong oder sahakong, sind böse Gespenster von der Gestalt und Grösse eines Menschen. Sie haben rothe Haare. Sie wohnen auf Lnnok-Bäumen (Ficus sp. div.) und in vielen Zaubergebüschen oder pahewan, wo man ihnen in kleinen, "rahan" genannten Häuschen Opfer bringt.

Sie machen zich ein Vergnügen daraus, die Menschen zu plagen, sie krank, besonders toll zu machen. Man glaubt auch, dass die Njaring in einem grossen Schmarotzerfarrnkraut (Platicerium alcicorne), das die Form eines 4-5 Fuss im Durchmesser grossen Nestes hat, hausen. Man nennt sie pahakong oder mambulong und wagt der Pflanze nicht nahe zu kommen."

Verder laat de studie van Grabowsky ons ter verklaring in den steek. Behalve de bovengenoemde njaring ziet men links tusscheu twee boomen een vrouwelijke figuur staan, kenbaar aan de lange, hangende haren en het korte rokje (saloi).

Naast den batang garing, die ter verhooging zijner luister twee martavanen aan den stam draagt, drijft een mannelijke figuur met lans gewapend een eigenaardige vogel voort, die blijkens de soortgelijke vogels onder de woning in vak $c$ wel een hoen zal moeten wezen. Rechts van den belofteboom gaan vier mannelijke figuren over een heuveltje, in doorsnee afgebeeld, zoodat men er de verborgen schatten kan zien: acht martavanen en zes gong's, netjes op twee rijen geschikt. De mannelijke figuren zijn als heusche Dajak's gekleed; zij dragen allen het baadje (badjoe) en het zitmatje (tapih).

De voorste draagt twee vederen op het hoofd, de anderen slechts een. Slechts de overmatig lange hoofdharen onderscheiden hen van de wezens op aarde. Met vreemdsoortige wapens in de hand achtervolgen zij een ondier.

Behandelt dit bovenvak het mysterieuse land der Sangiang's of luchtgeesten, zoo geeft het onderste vak $a$ het tegenovergestelde, de onderwereld te zien, het land der djata's.

Grabowsky deelt hierover het volgende mede (blz. 119). "Jetzt versteht man unter Djata eine Categorie von guten Geistern, die man nach ihrem Wohnsitz wohl die Götter des Wassers, resp. der Unterwelt nennen könnte. Jeder grosse Fluss hat verschiedene Djata, von welchen jeder seinen eigenen Bezirk beherrscht. Die mächtigsten derselben residieren nahe der Mündung der Fllüsse. Ausser diesen verschiedenen Distrikten der Flüsse, von welchen jeder von seinem Djata beherrscht wird, giebt es in jedem Fluss noch eine Menge einzelner Plätze, wo man meint, dass Djata sich aufhalten, 
verschieden in Macht, Ansehen u. s. w. Es sind aber solche Plätze nicht die eigentlichen Wohnstätten der Djata, sondern es ist dort nur der Eingang zu ihrem unter dem Wasser in der hohlen Erde liegenden Reiche, wo es ziemlich wie in unserer Oberwelt aussieht, nur alles schöner und prächtiger ist. Dort leben auch in Dörfern "tabak beang" (tabang beang oder tabak mangkok) genannt, die Knechte der Djata. Wenn sie im Auftrage der Djata's der Oberwelt einen Besuch machen, verändern sie ihre menschliche Gestalt in die eines Krokodils (badjai), indem sie die Krokodil-Gestalt als Kleid "klambi" überziehen."

Ook hier is niet alles duidelijk! Alleen de krokodil, als vermomming voor de knechten der djata's, hierboven beschreven, is onmiddellijk te herkennen naast enkele vreemdsoortige vischsoorten. Zeer de aandacht trekt het rijkversierde middenschot, dat aan de linkerzijde zes boven elkaar gestapelde gong's vertoont: evenzoo is de geheele voorstelling door randen met gong's omgeven. Dit komt eveneens met Grabowsky overeen: in het land der djata's ziet er alles veel mooier uit dan op aarde en dit geeft de Dajak weer, door een groot aantal gong's als voorwerpen van rijkdom aan te brengen. De uitgebogen punt met versierde uiteinde schijnt dan den ingang tot het eigenlijke djata-land te moeten voorstellen.

Dan bevinden zich nog twee raadselachtige dieren in golvende beweging door het water. Het zijn blijkbaar machtige wezens, want ieder draagt aan de vinnen en tusschen de horens van deu kop martavanen en wie geld heeft, bezit, naar Oostersche opvatting ook de macht. Intusschen is het niet duidelijk, of die twee draakvormige wezens de eigenlijke djata's moeten voorstellen of wel, dat hier de naga (zie Hardeland, blz. 370) is voorgesteld.

Vak $b$ is het raadselachtigste van alles! Links staan vier vrouwen tusschen opgerichte lanzen. De derde vrouw schijnt de voornaamste te ziju; de lange haren vormen een mantel en deze figuur is het meeste gedétailleerd. Dan volgt een kleine versiering met palen en guirlandes, twee zonderlinge boomvormen, waarvan de eerste weder eeu martavaau draagt en door een mannelijke figuur op zijde gegooid wordt. De laatste figuur, met zwaard en lans bewapend, schijnt aan de vrouwen iets mede te deelen.

In vak $c$ is een groote, Dajak'sche woning afgebeeld, staande tusschen boomen. Rechts staat de bekende sandoeng, waarin de beenderen der gestorven Dajak's bewaard worden, doch waarin nu een martavaan geplaatst is. Verder de singaran, de wapentrophee 
uit speren gevormd, uit een grooten martavaan oprijzend. De hooge middenstok wordt door een schedel bekroond.

Onder de wouing stampen twee vrouwen rijst; naast deze vrouwen zijn mandjes (met rijst?) opgehangen.

Viervoetige dieren en hoenders loopen rond de woning. Op het voorgedeelte van de trap staat een vrouw, vermoedelijk een blian, met een zward te zwaaien, dat in vorm zeer gelijkt op de baladau lebau, afgebeeld op plaat XVII, fig. 1 v. h. "Int. Archiv. f. Ethnographie." Bnd. V, 1892.

De twee woonvertrekken zijn vermooid met planken, waarop gong's en martavanen geschilderd zijn en het middenschot is versierd met zwaarden en bladen. In het eerste vertrek stormen twee vrouwen op een zittende, langharige figuur af, die in het tweede vertrek staande, een tak van een andere vrouw ontvangt.

In het bovengedeelte der woning slaan twee vrouwen op een gong, terwijl een Dajak met een tak gewapend, het dak beklimt. Antang's, neushoornvogels, vliegen overal heen en weder als goede voorteekens.

Links van het huis - bij nacht, blijkens de maan - varen twee vrouwen weg in een mysterieus vaartuig met den kop van een neushoornvogel en gestuurd door een zonderling dier, dat veel op de reeds genoemde njaring's gelijkt. Beide vrouwen staan in het vaartuig en hebben tusschen ziç een martavaan.

Rechts van het huis - bij dag, blijkens de zon - komt het vaartuig met dezelfde personen terug in hastige vaart, blijkbaar een goede boodschap brengend.

Naar alle warschijnlijkheid is hier het tiwah, het doodenfeest voorgesteld. Hierover deelt Hardeland in zijn bekend Woordenboek sub liau het volgende mede. "Liau, die abgeschiedene Seele. .... Sie geht zwar gleich in das Lewuliau, das Geisterland, hat aber dort noch keine eigentliche, ihr zugehörende Stütte; sie kommt denn auch oft von dort wieder zurück, durchstreift die Wälder, etc. hier auf Erden, und bewacht das Grab, den Sarg, worin ihr Leib liegt. Während dieser Zeit thut die Liau oft Schaden, macht Menschen krank, entweder um frühere Beleidigungeu zu rächen, oder weil sie jemand, welchen sie liebt, nachholen will.

Um ${ }^{1}$ sie zu befriedigen giebt man ihrdannzuesseu, opfert ihr Schweine, Hühner, etc., auch Bretter mit

1 Ik spatiëer. 
Häusern, heiligen Topfen etc. bemalt. Während des und durch das Tiwah, Todtenfest, wird dann die Salumpok liau feierlich u. für immer in das Lewuliau gebracht, durch den Sangiang (Luftgott) Tempon telon, und sendes Sclav Telon, in einem Banama sanamam, eisernen Schiffe, durch den Kiham apui, Feuerstrudel, hindurch".

De gespatiëerde deelen van dit citaat verklaren verschillende deelen van deze afbeelding. De priesteressen (blian's) spelen een hoofdrol en stampen de rijst voor de offerande. De hoenders en varkens, voor de offers bestemd, wachten in het ander gedeelte der woning hun lot af. Ook de door Hardeland vermelde planken, hier beschilderd met gong's en djawet's zijn aanwezig. Andere blian's verjagen door gescherm met wapens en het slaan op gong's de booze geesten, die de ziel voor haar afreis konden benadeelen en dit schijnt wel noodig blijkens de schorpioen, die onder de trap ontvlucht en de drie monsters, die het huis omringen. De voornaamste blian, staande op het plateau vóór de trap, roept de antang's, als voorspoedsboden op en deze verschijnen in zoo groote hoeveelheid, dat de Dajak aan den voet van de trap verbaasd opwaarts ziet.

Met de overbrenging van de ziel in het zielenschip heeft de inlandsche vervaardiger zich een groote vrijheid veroorloofd. Twee vrouwen, blian's, nemen hier de taak vau Tempon telon over en brengen den martavaan, die eerst in den sandoeng gestaan heeft naar het zieleland. Wel schijnt het bovennatuurlijke wezen, dat het zielenschip stuurt, of Tempon telon of zijn knecht telon te zijn. Doch is het niet aan te nemen, dat men de luchtgod zelf in zoo minwaardigen vorm zou afgebeeld hebben en is het waarschijnlijker, dat de onaanzienlijke figuur zijn knecht moet verbeelden.

Eigenaardig is het, dat bij deze voorstelling de blian's de taak van niemand minder dan Tempon telon vervullen en het duidt tevens aan, hoezeer de maker van dezen koker onder den sterken iuvloed der blian's gestaan heeft. En dit is zeer begrijpelijk, waar vooral deze vrouwen bij uitnemendheid de tradities van hun stam kennen.

Ook interessant is de rol, die de heilige pot, de martavaan bij dit doodenfeest speelt. In het uitvoerige artikel over "Potten en pottenbakkerij" in de "Encyclopaedie van Nederlandsch-Indië" staat hierover het volgende (bl. 323) : ".... Is dus de vereering der tempajan's een zuiver fetistische, oorspronkelijk moeten zij als mediums bij de vereering der afgestorvenen gediend hebben en vó́r dien tijd zullen zij derhalve ook reliekhouders zijn geweest. Werkelijk blijkt, dat de 
martavanen hebben gediend als bewarplaatsen van de asch van verbrande lijken, als urnen voor schedels en gebeente van familieleden. En bij de Moealang- en Sekadan-Dajaks dienen ze daartoe nog."

Het is dus ook hier zeer waarschijnlijk, dat deze martavaan de asch des overledenen, als symbool van ziju aardsche overblijfsel bevat en door de blian's in het zielenschip wordt meegenomeu. En deze aflevering schijnt hun gelukt te zijn, daar zij zonder martavaan en blijkbaar verheugd terugkomen.

Hiermede is dus de versiering van dezen bamboe-koker, met uitzondering van het raadselachtige vak $b$, verklaard. Het blijkt een allermerkwaardigst stuk te zijn, zooals van de Dajak's geen tweede bekend geworden is. En zondert men Javanen en Baliërs uit, dan is van geen ander Indisch volk een zoo uitvoerige, illustratieve behandeling aan te wijzen!

Het is ook tevens een dokument van Dajaksch kunstvermogen! Het tot nu toe bekende snijwerk in bamboe, hout en been, het weefsel, kralen- en vlechtwerk der Dajaks's beweegt zich uitsluitend op het gebied der toegepaste kunst, waarbij niet vergeten mag worden, dat het traditie-kunst is, kunst van vader op zoon, door eeuwen heen gegroeid en ontwikkeld. Het individueele ontbreekt daarin vrijwel.

En dat is artistiek juist het belangrijke in dezen koker, dat hier een geheel nieuw gebied betreden wordt, het afbeelden van gebeurtenissen uit de Dajak'sche mythologie, terwijl de uitwerking rijker, uitvoeriger is dan de bekende, beschilderde planken met het "zielenschip".

Natuurlijk kunnen op enkele détails aanmerkingen gemaakt worden. De gezichtsbehandeling is hier en daar primitief, de twee rijststampende vrouwen zijn het slechtst in verhouding. Doch als geheel is het een schitterend staal van inlandsch illustratie-vermogen, dat alles behalve primitief is!

Hoe smaakvol en geestig is het geheel gekomponeerd! Het toont een veelheid van de handelingen, die toch rustig en duidelijk blijft. De beweging der personen - in primitief werk een zwak punt is overal gelukkig en zelfs de teekenfout in de vrouwen is op rekening van dit streven naar beweging te stellen. Elk vak is op zich zelf met groote, artistieke kennis verdeeld; nergens hinderlijke, leege plekken, nergens een teveel in motieven. En hoeveel smaakvolle fantasie in die boomen van het sangiang-land, hoe helder-duidelijk 
dat onderscheid tusschen sangiang- en djata-land. Hoe juist gevonden is dat gong-ornament als afsluiting van het djata-land! Deze herhaling van cirkels verhoogt de beweegelijkheid van de afgebeelde dieren!

De latste te bespreken koker bevindt zich als $\mathrm{N}^{\circ}$. M. 106 in de Ethnographische verzameling van het Genootschap Nat. Art. Mag. te Amsterdam en is door Prof. Molengraaff van de Ot-Danom's meegebracht. Dit exemplaar is minder fijn bewerkt dan de vorige; een gesneden ornament met weggespleten fond, terwijl de vorige gegraveerd oanament vertoont. Door dit suijden zijn waarschijnlijk verschillende détails verongelukt.

Ook dit is een mooi werkstuk! Onregelmatig, maar toch zonder onrustig te doen, zijn eenige boomen afgebeeld, een levendig beweeg van takken en driebladig loover, waarin allerlei vogels en dieren vliegen en springen. In het midden-gedeelte twee paalwoningen, weer in doorsnede afgebeeld. Als afsluiting onder en boven een dubbele ornamentrand, die begrensd wordt door een strenge toempal-rij. En deze sobere afsluiting draagt er sterk toe bij, het woelige hoofdvak rustiger te doen stemmen.

In het eerst doet deze voorstelling denken aan een poging, huizen in een bosch af te beelden, doch bij nader inzien blijkt dit niet het geval te zijn. In den rechter onderhoek rust bijv. een boom op een naga. Onder het linkérhuis bevinden zich twee naga's en een krokodil, die eveneens wijzen op meer dan gewone beteekenis.

In de twee woningen, verschillend ingedeeld, heerscht een ongewoon vertier. Onder beide woningen zijn vrouwen druk bezig met rijststampen. Talrijke gong's en martavanen zijn uitgestald en toonen evenals de dansende figuren, dac hier een feestelijk tafereel door den inlandschen snijder behandeld is. Ook de nok van het dak is versierd en op beide daken is een vogel neergestreken.

Naar alle waarschijnlijkheid is een der beide feesten, die Grabowsky op blz. 130-132 beschrijft, afgebeeld.

In het citaat zijn de spatieëringen van mij afkomstig en duiden de plaatsen aan, die op de afbeelding betrekking hebben.

Radja ontong, der König des Glückes, auch radja blawang bulau, d. h. König der goldenen Thüre genannt, ist der Herr alles Glücks und Vortheils. Seine Frau heisst Putir Sawawalang langit; Becker p. 435. Er wohnt über dem Himmel der Sangiang, dicht bei dem Himmel von Mahatara.

Wer Unglück hat oder wer sein Giück noch zu vermehren se Volgr. I. 
wünscht, muss von ihm Glück erbitten, "blaku ontong”. - Wer lange leben will, muss blaku tahaseng, d. h. um (langen) Athem bitten. Ein solches Opferfest dauert zwei Tage und zwei Nächte. Ein Basir (tukang tawor) und sieben Blians sind dabei beschäftigt. In der ersten Nacht wird durch die Zaubersprüche derselben alles Sial (Unglück) vertrieben. Mann nennt dies manganan sial oder Sial hadjandi. (Hupe p. 149). Es geschieht auf folgende Weise: In der Nähe des Hauses, das von den Sial gereinigt werden soll, wird ein zuckerhutförmiges Zelt aus Zeug oder Matten errichtet. Auf der Spitze des Zeltes sitzt ein Basir und sucht durch Streuen von Reis den Sial das Eindringen in das Zelt zu wehren. Die Blians mit hölzernen Schwerteru bewaffnet, dringen in das Haus, fechten in allen Räumen umher, kommen wie rasend wieder zum Vorschein, schlagen unter der zahlreich versammelten Menge umher, bestürmen das Zelt um auch daraus die Sial zu vertreiben, können aber nicht eindringen und also ist dies auch den Sial nicht möglich. Sie laufen dann bald in das Haus, bald an den Fluss um die sich an die Schwester heftenden Sial abzuwaschen. Zuweilen hört man aus einiger Entfernung den Ton einer Kesselpauke, welche Töne die Herausforderung eines nahenden Spukes, Kambä, etc. bedeuten; dann fliehen die Blians (Hupe p. 149).

Einfacher und billiger als die eben beschriebene Art die Sial zu vertreiben, und darum allgemeiner im Gebrauch ist die folgende Art: Man macht ein 2 Spannen hohes Häuschen aus Bambu, "huma sial" genannt. Dahinein stellen die Blian die Sial, die sie durch Fegen ' uud Reisstreuen im Hause gefangen haben. Zuweilen legen sie noch ein Huhn dazu und lassen die huma sial den Fluss hinabschwimmen. Diese gelangt bis zu einem in der Mitte der See befindlichen kesselförmigen Schiff, "banama bunter", und wirft da seine Ladung ab, so dass dieses Schiff alle körperlichen und sittlichen Schäden der Menschheit enthält, von wo sie dann wieder über die Menschheit ausgestreut werden; Hupe p. 150.

In der zweiten Nacht des blaku ontong werden nun die Opfer gebracht und zwar sieben Hühner, ein $\mathrm{Ei}$, sieben Blätter voll Reis, sieben Bambu voll Reis, ferner Backwerk, Früchte und Zuckerrohr.

Es wird zu dem Fest eine pasahontong; d. h. Hütte

1 Geschieht mit einem, Papas pali genannten Besen, der aus Blättern der Sawang-Kakambat und Talengkak-Pflanze gebunden und mit Blut und Reiswasser befeuchtet ist. Man schwingt diesen Besen über dem Menschen oder durch das ganze Haus, aus dem man den Sial entfernen will. 
des Glücks hergestellt. Sie ähnelt einem Samburup, der zum Opfer für Djata gebraucht wird, nurdass durch eine Art Vorhalle zu der eine Treppe (lampat oder hedjang), hinaufführt, die pasah ontong länger als breit ist; c. 1.50 M. lang und l M. breit.

Die genannten Opfer werden auf dem Hauptplateau niedergesetzt, dessen dachartiges Gestell wie beim Samburup mit möglichst neuem Zeuge, womöglich mit Kadandang (feuerrothes Baumwollenzeng) überdeckt wird. Darüber ragt die aus TunjungHolz geschnitzte Spitze einer Ananasfrucht hervor. An den Ecken der pasah ontong hängen spitze, geffochtene Körbchen, "srangan hambaruan", in welche geölter Reis gethan wird, lauter vollständige Körner; ist der Reis am zweiten Tage rissig, so ist das ein besonders günstiges Zeichen für den Erfolg des Festes.

In dem Ha uptraum der pasah ontong die mit Guirlanden aus frischen Pinangblüthen (Areca Catechu) und gefärbten Gräsern behangen ist, werden garantongs (kupferne Kesselpauken) und sonstige Werthsachen hineingestellt, namentlich auch eine Pyramide welche durch sechs auf einander gesetzte, mit Reis gefüllte Teller oder garantongs gebildet wird, und einige kürzere Stücke Rotan. (Nach Hardeland 3 Gantang enthülsten Reis, ein wenig Gold und einen Rottan, der eine Klafter eine Elle eine Spanne und drei Fingerbreit lang ist).

Ein Basir streut nun Reis nachallen Richtungen aus, um einem Antang (Haliastur intermedius) herbeizurufen. Fürden Lohneines Huhnessoll Antang einem Sangiang (meist Tempon Telon) den Wunsch des Festgebers mittheilen. Tempon Telon erscheint nun um die Seelen (gana) der Opfer die auf der pasah ontong liegen, dem radja ontong zu überbringen. Das Gefolge von Tempon Telon bleibt in der Vorhalle der pasah ontong zurück, wo für dasselbe auch einige Speisen niedergelegt werden. Tempon Telon geht uun zum Radja ontong und überbringt diesem den Wunsch des F'estgebers, er möge Glück (und langes Leben) von allen möglichen Machthabern und angeseheneu Leuten auf ihn vereinigen. Radja ontong giebt dem Sangiang ein wenig Gold, das dieser den Blians überbringt, womit diese, den unter der pasal ontong liegenden Reis, das Gold und den Rottan bestreichen. Hat sich dann am Ende des Festes der Reis oder das Gold um etwas vermehrt, und ist der Rottan etwas länger geworden, so ist das ein Zeichen, dass wirklich durch den Radja ontong 
Glück mit jenen Dingen verbunden worden ist. Der Festgeber isst den Reis dann auf, schmiedet das Gold an seine Ohrscheiben und legt den Rottan unter sein Kopfkissen. Er meint dann zuversichtlich auf Glück rechnen zu dürfen.”

Hier is dus slechts een deel van het feest afgebeeld! Waarschijnlijk omdat de inlandsche snijder de bizondere capaciteiten miste, die de kunstenaar van den vorigen koker in zoo hooge mate bezat.

Maar dit neemt toch niet weg, dat ook deze Dajaksche koker, ondanks de primitieve voorstelling dier figuren onder de zeer interessante bamboe-kokers van onzen Archipel mag gerekend worden.

Elberfeld, Februari 1910.

N A S C H R I F T.

Bij een kort bezoek aan 's Rijks Ethnographisch Museum te Leiden in Aug. 1910 vond ik een nieuwe aanwinst van het Museum, een bamboe-koker uit de Z.- en O. Afd. als ser. 1619-18. Deze koker, grover bewerkt dan de hier afgebeelde, is in 3 vakken verdeeld. Het bovenste toont een vluchtige herhaling van vak $d$ in fig. 4 , het middelste geeft de reeks vrouwen weer van vak 4 in fig. 4 , terwijl het onderste deel een jacht op dieren en een gevecht voorstelt. Op den koker ser. 1596-1 uit dezelfde afdeeling en bij het nieuw rangschikken der kasten gevonden, is in snijwerk een uitvoerig boom-ornament aangebracht, terwijl deze koker rood geverfd is.

Deze vondst bewijst alweer, hoe ook op dit illustratief gebied een traditie-kunst onder de Dajak's aanwezig moet zijn.

L. 


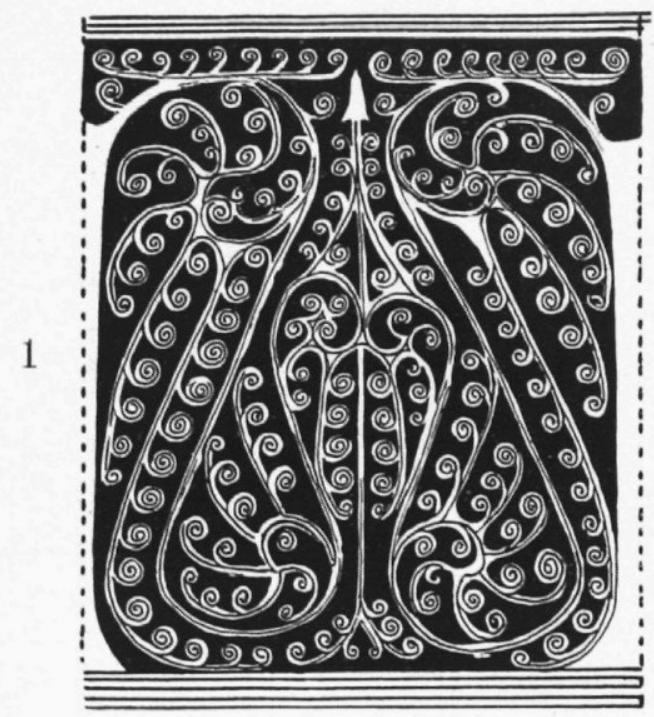

Lengte $81 \mathrm{cM}$.

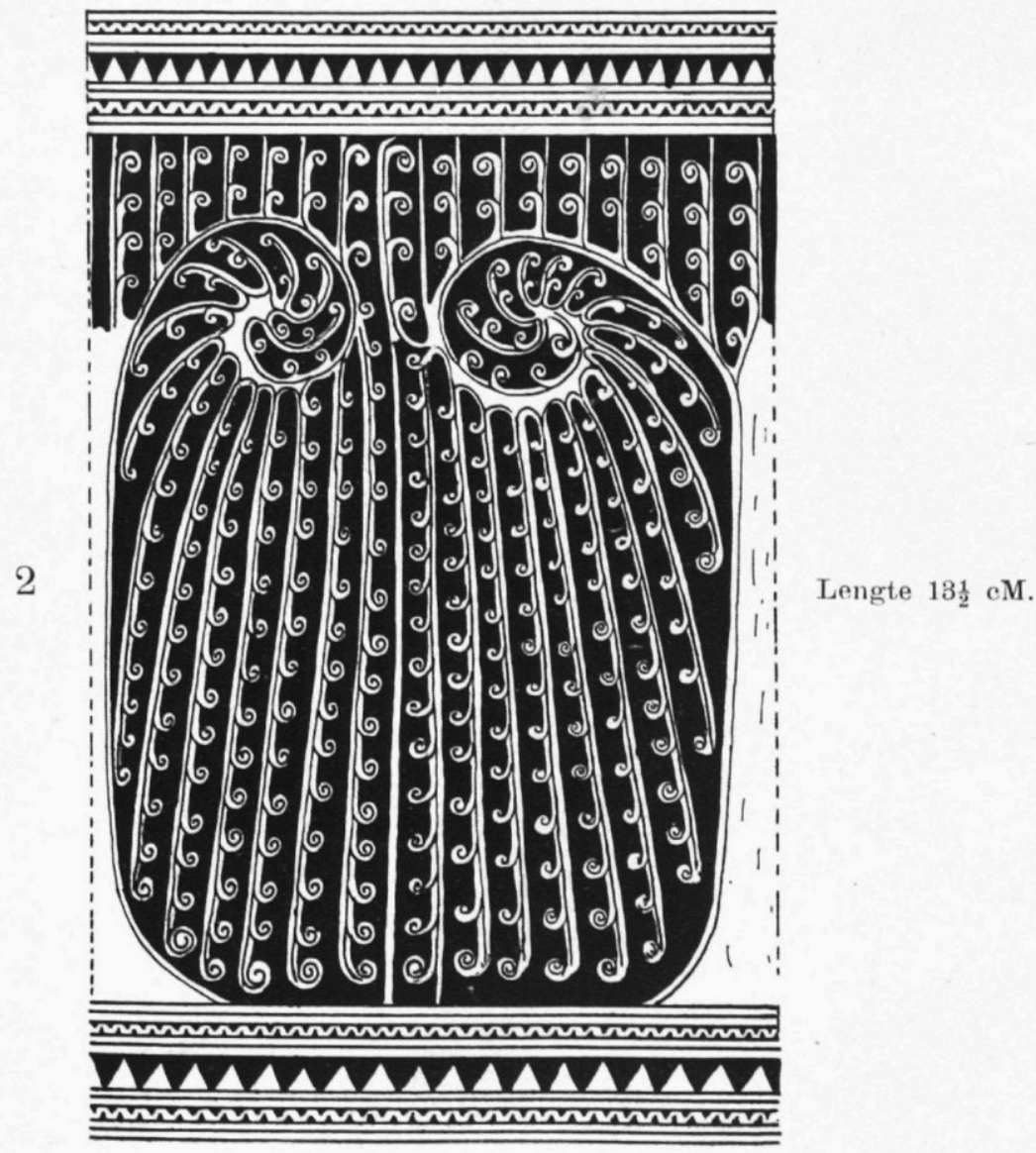




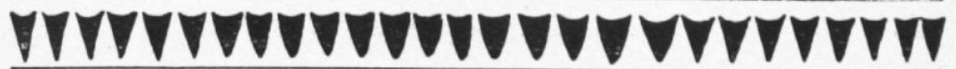
3 N . 1.76

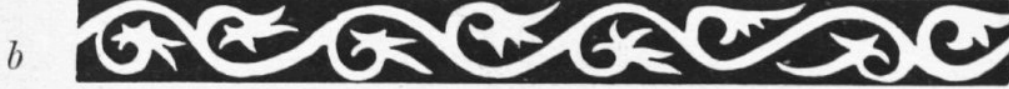

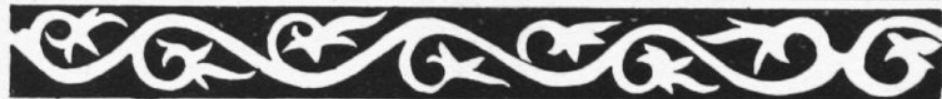
站 1 ind
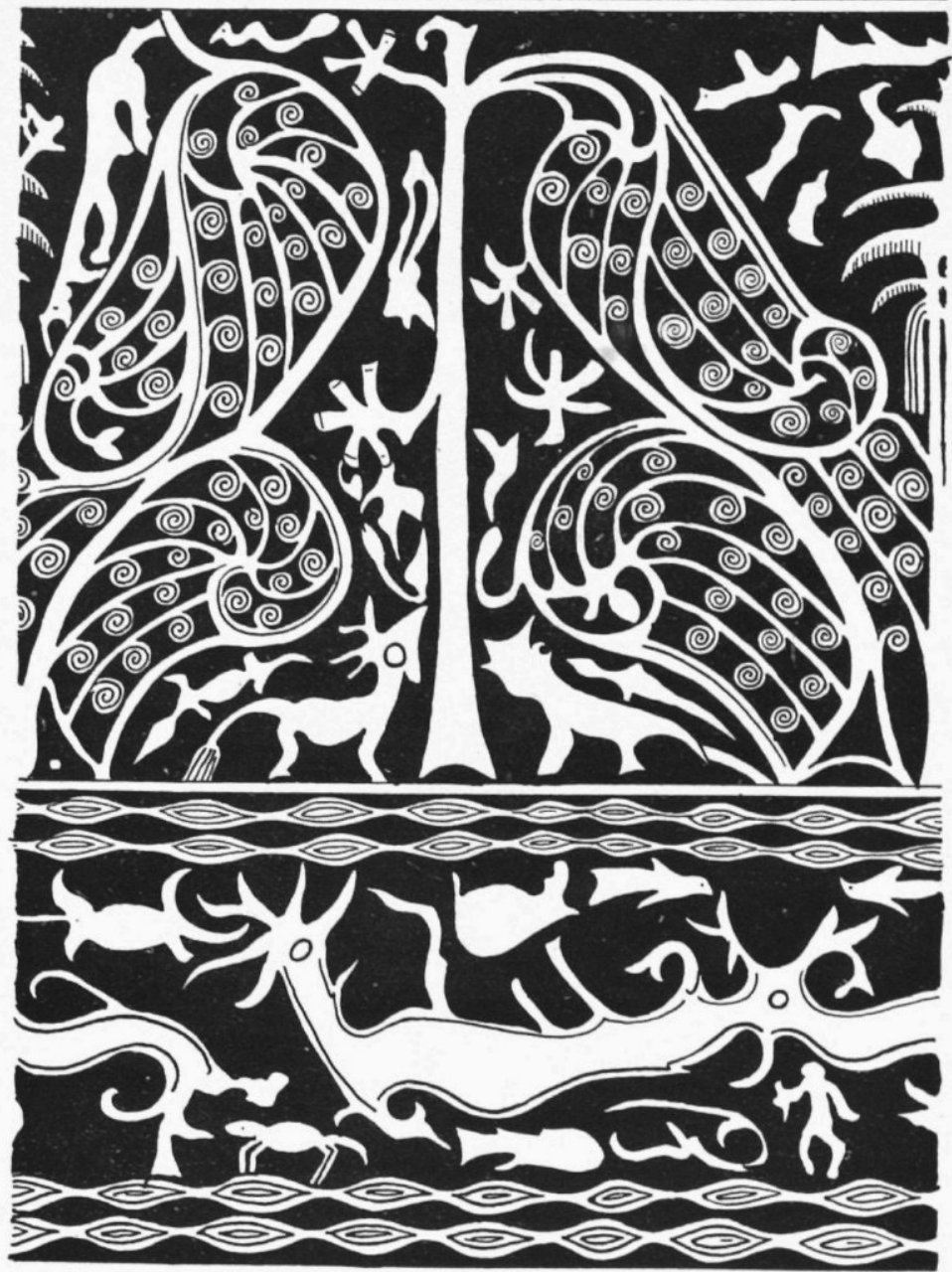


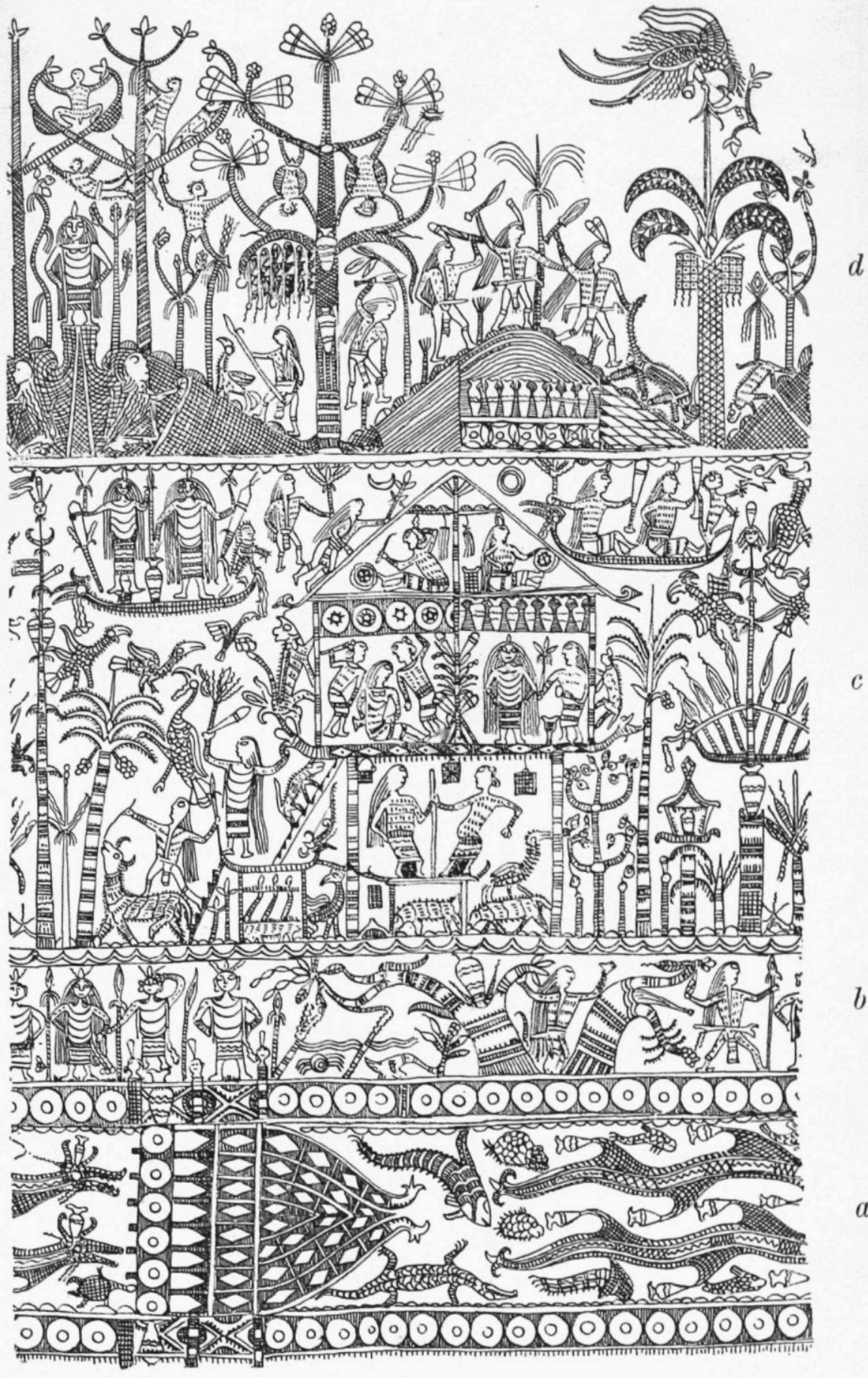




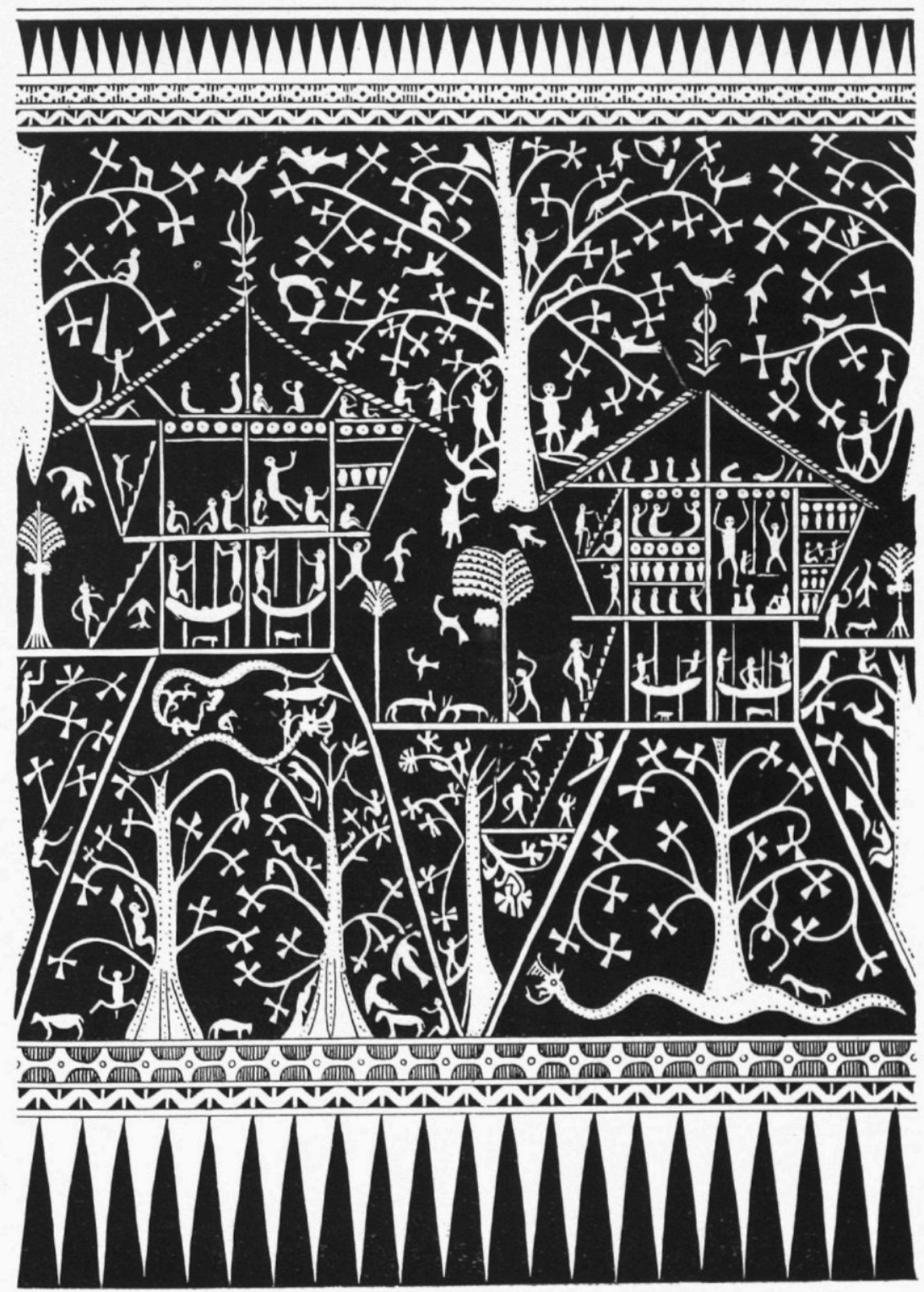

